\title{
Heterosexist Attitudes and Team Cohesion in Women's Collegiate Athletics
}

\author{
Elizabeth M. Mullin \\ Springfield College
}

\begin{abstract}
The purpose of the current study was to establish the nature of the quantitative relationship between heterosexist attitudes and team cohesion. The researcher also examined how individual factors of the multidimensional constructs of heterosexist attitudes and team cohesion substantiate that association using the Social Identity Approach (Abrams \& Hogg, 2004; Hogg \& Abrams, 1988) as the theoretical framework. A canonical correlational analysis revealed a significant negative correlation between the four subscales of the Heterosexist Attitudes in Sport-Lesbian scale (Mullin, 2013) and the four subscales of the Group Environment Questionnaire (Carron, Widmeyer, \& Brawley, 1985) in a national sample $(N=621)$ of female collegiate student-athletes, $\Lambda=.91, p<.001, \eta^{2}=$ .07. As heterosexist attitudes increased, perception of team cohesion decreased. The Language Behaviors and Inclusion Behaviors subscales of the HAS-L and the task components of the GEQ were the strongest contributors to the relationship among the constructs. By developing and supporting inclusive environments, coaches and administrators may be reducing harmful heterosexist attitudes that are disruptive to achieving the team's objective.
\end{abstract}

Keywords: homophobia, homonegativism, group dynamics, sport

Since the implementation of Title IX of the Educational Amendments in 1972, female participation in sport has grown exponentially (Acosta \& Carpenter, 2014) to the point of being commonplace in the United States. Yet the shift to include women in a historically male-dominated sphere has not occurred without consequences. Traditionally, sport was a tool used to teach young boys how to mature into men because athletic pursuits required the demonstration of ideal masculine traits (e.g., leadership, aggression, and violence; Anderson, 2009; Kauer \& Krane, 2013). As the adjectives that defined acceptable femininity (e.g., gentle, nurturing, fragile) were not associated with sport, the common belief was that sport would have undesired masculinizing effects on women, undermining accepted societal gender roles (Fisher, Knust, \& Johnson, 2013; Griffin, 1998). As both sport and lesbianism were associated with, if not conventionally defined by, the word masculine,

The author is with the Department of Physical Education and Health Education, Springfield College, Springfield, MA. Address author correspondence to Elizabeth M. Mullin at emullin@springfieldcollege.edu. 
female athletes were denigrated with the label of "lesbian" (Griffin, 1998), a term stigmatized by the homophobic and heterosexist environment endemic to sport (Hawes, 2001).

Homophobia, as defined by Weinberg (1972), is an affective construct focused on the fear of being in close proximity of lesbians and gay males. A related, but conceptually different construct, heterosexism, is the belief that a heterosexual orientation is the only acceptable form of sexual expression and all other forms are considered deviant or abnormal (Griffin, 1998). While homophobia and heterosexism are separate constructs (e.g., one can privilege heterosexuality without being irrationally afraid of being physically close to lesbians or gay males), the two are intertwined at the individual, institutional, and cultural levels (Herek, 2000). Homophobic and heterosexist behaviors (e.g., labeling all female athletes as mannish lesbians) by both men and women have been used to diminish and marginalize the efforts and accomplishments of female participation in sport (Blinde \& Taub, 1992; Griffin, 1998; Kauer \& Krane, 2006).

Historically, many coaches and administrators believed that conformity to the heterosexual feminine ideal among female athletes was the optimal path to maintaining team cohesion while simultaneously preserving the reputation of the program (Blinde \& Taub, 1992; Hawes, 2001; Melton \& Cunningham, 2012). The existence of lesbians on a team was perceived to be a "problem" to be ignored or removed (Blinde \& Taub, 1992; Calhoun, LaVoi, \& Johnson, 2011; Krane, 1997; Melton \& Cunningham, 2012; Rotella \& Murray, 1991; Wellman \& Blinde, 1997; Wolf-Wendel, Toma, \& Morphew, 2001). Researchers have argued that the opposite is likely true: it is the prevalence of heterosexist attitudes, not the existence of lesbians themselves, which is likely harmful to cohesion (Krane, 1997; Vealey, 1997). The ability to build a cohesive unit may be impeded due to heterosexist norms which separate female athletes into two groups: women who meet (or strive to meet) the hegemonic feminine ideal (White, heterosexual, gentle, nurturing, etc.; Krane, Choi, Baird, Aimar, \& Kauer, 2004; Krane \& Kaus, 2014), and all others who are labeled as a lesbian (Mullin, 2016). In an effort to avoid the lesbian label, some female athletes may try to improve their social status either by "performing femininity" (Krane, 2001) or instead themselves engaging in the marginalization of perceived lesbian female athletes (Krane \& Kauer, 2007; Sartore \& Cunningham, 2009), creating further divisions among women in sport.

While researchers have demonstrated that sexual orientation diversity in a sport group setting has the ability to improve social bonds (Fink, Burton, Farrell, \& Parker 2012; Litchfield, 2011; Stoelting, 2011), creativity, and performance (Cunningham, 2011a, 2011b; Cunningham \& Melton, 2011) little is known about the direct link between heterosexist attitudes and team cohesion. Therefore, the purpose of the current study is to examine the quantitative relationship between the two multidimensional constructs of heterosexist attitudes and team cohesion.

\section{Theoretical Framework and Review of Literature}

Social Identity Approach (Abrams \& Hogg, 2004; Hogg \& Abrams, 1988), consisting of Social Categorization Theory (Turner, 1987) and Social Identity Theory (Tajfel \& Turner, 1979), is an appropriate theoretical framework to examine the 
relationship between heterosexist attitudes and team cohesion, as prejudicial attitudes enacted toward sub groups in a team environment will likely result in division, not unification. Self Categorization Theory (Turner, 1987) focuses on how individuals use salient attributes to categorize their own social identity and the social identity affiliations of others. Various attributes could be used in the categorization process, such as a team jacket to identify team membership, physical attributes to identify gender, or a butch-hair style to identify perceived sexual orientation. According to Social Identity Theory, humans are inherently motivated to maintain a high self-concept (Tajfel \& Turner, 1979). Individuals have two primary means to preserve self-concept through their social identities: strengthening of attachment to a group with high social capital or disparaging individuals categorized in other groups, therefore reducing the social capital of the out-group (Bruner, Dunlop, \& Beauchamp, 2014). According to the Social Identity Approach, the stigma of the lesbian label encourages female athletes to identify more strongly with the hegemonic feminine ideal, the high-capital group and distance oneself from the others who are devalued by the label (Krane et al., 2004; Krane \& Kaus, 2014).

Researchers have historically found that female athletes have acted in this manner. Blinde and Taub (1992) conducted a study of Division I female collegiate athletes who identified as heterosexual. Athletes demonstrated an unwillingness to talk about or acknowledge lesbians in sport. When they did discuss lesbian athletes in sport, they relied on false and prejudicial stereotypes. The authors contended that the lack of discussion and continuation of harmful stereotypes sustained a homo-negative atmosphere in sport that was detrimental to heterosexual and lesbian athletes alike. In her study of female lesbian college athletes, Krane (1997) found that coaches and administrators urged the team to present a feminine image. Nonconforming behaviors were penalized through verbal condemnations and threats of loss of scholarships or roster spots. The participants were well aware of the lesbian label within collegiate athletics. The athletes witnessed pejorative name-calling and prejudicial statements regarding perceived sexual orientation made about other athletes or teams from teammates, classmates, or coaches. In 2006, Kauer and Krane conducted similar interviews with heterosexual, lesbian, and bisexual female athletes. The lesbian label was still characterized as pervasive in sport. One athlete identified that stereotypes of female athletes were based on various salient characteristics and mannerisms: "the way they carry themselves, the way they walk, the way their hair is, the cockiness on the playing court" (p. 47). Krane (1997) also identified that many of the lesbian athletes actively distanced themselves from the label to avoid discrimination, choosing to pass as a heterosexual athlete to avoid the stigma attached to being a lesbian. The choice to overtly demonstrate heterosexuality and/or femininity to avoid the lesbian label was reported in a number of other studies (Krane, 2001; Melton \& Cunningham, 2012; Shakib, 2003).

More recent researchers have indicated that homophobic and heterosexist attitudes in collegiate athletes are decreasing, suggesting overall improvements in women's athletics (Kauer \& Krane, 2006; Roper \& Halloran, 2007; Southall, Nagel, Anderson, Polite, \& Southall, 2009). Generally, female athletes and coaches have reported more positive attitudes toward gay males and lesbians than male athletes and coaches have toward gay males (Roper \& Halloran, 2007; Southall et al., 2009; Vargas-Tonsing \& Oswalt, 2009). Stoelting (2011) described that lesbians who chose to disclose their sexual orientation to their teammates did so because they 
felt that honesty was critical in developing potential friendships and social bonds on a team. The act of disclosure may have served to normalize the lesbian identity in the team environment. Fink et al. (2012) found that current or former female collegiate athletes who had come out as lesbian or bisexual identified that their teams were open and accepting. They also reported that the team acted as an agent for social change in accepting various sexual identities and normalizing the act of disclosure. In men's collegiate athletics, Adams and Anderson (2012) suggested that the experience of a male soccer player coming out to his team at a midwestern Catholic university had a positive influence in building cohesion. Social Identity Theory posits that individuals will conform to social norms to maintain their bonds with a team. If coaches and peer leaders develop homo-positive norms, disclosure of sexual identity might provide an avenue of team growth, instead of disruption (Krane \& Kaus, 2014). For example, normalization of acceptance via a diversity strategy in athletic administration resulted in improved outcomes in the Sport Management literature. Cunningham (2011a, 2011b) reported that departments that had both high sexual orientation diversity and an inclusive diversity strategy were more likely to have better performance outcomes and greater creativity than those without a diversity strategy.

Despite the breadth of research on homophobia and heterosexism in women's athletics, little is known about the quantitative link between heterosexist attitudes and team cohesion. To the current researcher's best knowledge, only one known group of researchers has attempted to quantitatively connect the constructs of homophobia and team cohesion in women's collegiate athletics (Forbes, Stevens, \& Lathrop, 2002). Female collegiate athletes reported a high degree of comfort toward lesbians, and a low belief that lesbianism is deviant or changeable, as measured by the Modern Homophobia Scale (Raja \& Stokes, 1998). There was also no difference between the social aspects of team cohesion and responses to homo-negative or homo-neutral vignettes. The authors concluded that female athletes did not hold hostile attitudes toward lesbians. However, the athletes did not respond more negatively to the homo-negative vignette than the homo-neutral vignette, suggesting an internalized acceptance of the homophobic discourse and heterosexist behaviors presented in the vignette. A limitation of the Forbes et al. study was the use of a general psychological questionnaire. The questionnaire may not have been sensitive enough to assess attitudes in the context of women's collegiate athletics, where female athletes are constantly at odds with the stigma of the lesbian label. In the current study, a sport-specific measure of heterosexist attitudes was employed to better elucidate the theorized link between heterosexist attitudes and team cohesion in women's collegiate athletics. According to Social Identity Approach, individuals with higher heterosexist attitudes will have greater difficulty associating with sport given the pervasive lesbian label. Consequently, the first hypothesis examined in the current study was:

Hypothesis 1: As heterosexist attitudes in female collegiate athletes increase, team cohesion is expected to decrease.

One additional benefit of quantitative assessment is the ability to distinctively evaluate a construct by its multidimensional component parts. In the current study, heterosexist attitudes were measured by examining the cognitive, the affective, and the behavioral components. A secondary purpose of the current study was to 
investigate the individual contribution of each dimension of heterosexist attitudes and cohesion when examining the relationship between the two. Given that one method to increase oneself-concept through social identity is denigration of the out-group through verbal or exclusionary behaviors, it is expected that behavioral heterosexist attitudes will more strongly contribute to the relationship between heterosexist behaviors and cohesion. The second hypothesis examined was:

Hypothesis 2: Behavioral heterosexist attitudes will have a stronger negative relationship with perceived team cohesion than cognitive and affective heterosexist attitudes.

Team cohesion consists of two theoretical components: (1) individual's attractiveness to the group versus the individual's perception of group integration and (2) task versus social (Carron, Widmeyer, \& Brawley, 1985). Attraction to group is defined as the extent to which an individual is drawn to membership with a group where group integration is the individual's own perception of how closely the group is unified. Task elements refer to the extent to which a team works together toward objectives, such as winning. Social elements refer to the extent to which the team is motivated to be inclusive and "get along" (Carron, Brawley, \& Widmeyer, 2002). Subsequently, team cohesion was divided into four theoretical dimensions from the combination two elements: Individual Attraction to the Group-Social (ATG-S), Individual Attraction to the Group-Task (ATG-T), Group Integration-Social (GI-S), and Group Integration-Task (GI-T; Carron et al., 1985). According to the Social Identity Approach, after an individual categorizes a group as one with lower social status (i.e., women's athletic team associated with the lesbian label), she will demonstrate lower desire to socially affiliate with that group, resulting in lower social cohesion. The third hypothesis tested in the current study was:

Hypothesis 3: As heterosexist attitudes increase, social elements of team cohesion (ATG-S and GI-S) are expected to decrease.

To the best of the researcher's knowledge, no direct theoretical link has been suggested between heterosexist attitudes and task elements of cohesion. Empirically, Cunningham (2011b) identified that employment of inclusionary strategies in an Athletic Department (e.g., norming lower heterosexist attitudes in a group environment) predicted improved performance. The inverse relationship may also be true. One's perception that the group is united to attain team objectives may be negatively influenced by prejudicial heterosexist attitudes, due to the lower desire to affiliate with the lower status group. Consequently, a fourth hypothesis was tested:

Hypothesis 4: As heterosexist attitudes increase, task elements of team cohesion (ATG-T, and GI-T) are expected to decrease.

\section{Method}

\section{Participants}

Using a random number generator on a calculator (TI-83, Texas Instruments, Dallas, TX), 200 colleges and universities were randomly chosen from the list of all NCAA-affiliated institutions with a women's varsity athletics program across 
the United States during the 2012-2013 academic year. The Directors of Athletics (ADs) were emailed, requesting permission to contact their head coaches. Of the 200 ADs contacted, 41 granted permission (21\%), 22 denied permission (11\%), 9 required a follow-up with their own institution's Institutional Review Board (IRB), and 122 did not respond (63\%). No follow-ups were made with additional IRBs. After permission was granted, emails were sent to the head coaches requesting permission to conduct the study with their student-athletes. Follow-up emails were sent to ADs and coaches two weeks after the initial e-mail and again one week later. Of the 289 head coaches emailed, 92 granted permission (32\%), 7 denied permission (2\%), and 190 did not respond (66\%). Response rates for the study are similar to other studies on similar content, using similar recruitment strategies (Mullin, 2013, 2016). After receiving permission from the head coaches, the researcher provided the coach with a brief description of the study and the study URL to e-mail to the student-athletes. Participants $(N=641)$ began the questionnaires. Twenty individuals were removed from the study for incomplete surveys or not meeting inclusions criterion (e.g., individual was a coach, not a student-athlete).

The final analysis consisted of 621 female student-athletes from 33 colleges and universities from Division I $(n=47)$, Division II $(n=259)$, and Division III $(n=292)$ institutions. Twenty-three participants did not indicate what institution they were attending. On average, participants were 19.46 years old $(S D=1.21)$ and had completed 2.95 semesters of college $(S D=2.31)$. Participants represented 15 different sports (Basketball, Crew, Cross Country, Equestrian, Field Hockey, Golf, Gymnastics, Lacrosse, Rugby, Track and Field, Soccer, Softball, Swimming, Tennis, and Volleyball). Individuals reported being a member of that team for an average of 1.73 seasons $(S D=1.38)$. A majority of the participants $(n=550)$ had not competed in a competition in the 24 hours before responding to the questionnaires. Of those who did, 18 won, 31 lost, and three tied.

A large majority of the participants $(n=573)$ indicated personally knowing at least one lesbian, gay male, bisexual, or transgender (LGBT) individual. Of those who did know at least one LGBT individual, they estimated that they personally knew $11.50 \pm 16.23$ (median = 7.00) LGBT individuals. Regarding participant sexual orientation, 439 participants reported being exclusively heterosexual and 20 participants reported being exclusively homosexual. The remaining participants ( $n=140)$ reported falling somewhere between exclusively heterosexual and exclusively homosexual on the Kinsey scale (Kinsey, Pomeroy, \& Martin, 1948) or they declined to answer $(n=22)$.

\section{Instrumentation}

Heterosexist Attitudes in Sport-Lesbian Scale. The Heterosexist Attitudes in Sport-Lesbian scale (HAS-L; Mullin, 2013) is a 14-item sport-specific questionnaire that measures heterosexist attitudes toward lesbians in collegiate athletes. Response options range from 1 (strongly disagree) to 5 (strongly agree). The scale was devised using the tripartite model of attitudes (Zanna \& Rempel, 1988), which contends that attitudes are the summative evaluation of the cognitive, affective, and behavioral. An additional subscale, Avoidance of the Lesbian Label, was added to more strongly ground the scale to the literature regarding heterosexism in women's athletics (Mullin, 2013). The scale consists of four subscales: (1) Cognitive/Affective, (2) Language Behaviors, (3) Inclusion Behaviors, and (4) Avoidance of the 
Lesbian Label. The Cognitive/Affective subscale (6 items) is defined as stereotypes, schemas, thoughts and emotions that inform one's belief that heterosexuality is privileged and the only acceptable form of sexual expression while all other forms are consider abnormal. A sample item from the Cognitive/Affective subscale is "I believe 'out' lesbians negatively affect the team environment." Previous measures of composite reliability have ranged from .81-.85 (Mullin, 2013, 2016). In the current study, the Cognitive/Affective subscale had a Cronbach's alpha of .83. The Language Behaviors subscale ( 3 items) is defined as behaviors related to speaking that demonstrate the privilege of heterosexuality. A sample item is "I have used terms like 'dyke' and 'homo' as put-downs in conversation with teammates." Previous measures of composite reliability have ranged from .70-.83 (Mullin, 2013, 2016). Internal consistency of the Language Behaviors subscale was .69. The Inclusion Behaviors subscale ( 3 items) is defined as behaviors in which individuals include or exclude others based on the belief that heterosexuality is privileged. A reverse scored example item from the Inclusion Behaviors subscale is: "I socialize with teammates regardless of sexual orientation." Composite reliability assessments have ranged from .60-.79 (Mullin, 2013, 2016). Cronbach's alpha for the Inclusion Behaviors subscale was .64. The Avoidance of the Lesbian Label subscale (3 items) is defined as thoughts and behaviors that demonstrate a desire to distance oneself from being called a lesbian as a result of her participation in sport. An example item from the Avoidance of the Lesbian Label subscale is: "I have avoided participating in certain sports because of the association with lesbianism." Previous composite reliability assessments have ranged from .50-.64 (Mullin, 2013, 2016). Internal consistency of the Avoidance of the Lesbian Label subscale in the current study is .68.

Scores of each subscale are averaged, where higher scores on each subscale are indicative of higher heterosexist attitudes. The HAS-L has demonstrated consistent evidence of construct validity, reporting acceptable fit statistics after conducting a confirmatory factor analysis (Mullin, 2013, 2016). In Mullin (2016), the subscales of the HAS-L adequately correlated with the Attitudes toward Lesbians subscale of the Attitudes toward Lesbians and Gay Males (ATLG) scale short form (Herek \& McLemore, 2011), providing evidence of concurrent criterion-related validity. The subscales also significantly correlated with the Attitudes toward Gay Males subscale of the ATLG short form, measures of religiosity, political affiliation, age, number of LGBT people personally known, consistent with previous theoretically and empirically identified correlates of homophobia and heterosexist attitudes. All four subscales demonstrated temporal stability over an approximate 4-week period (ICCs: Affective/Cognitive $=.91$, Language Behaviors $=.81$, Inclusion $=$ .64 , Avoidance of the Lesbian Label $=.70$ ).

Group Environment Questionnaire. Participants were asked to complete the 18-item Group Environment Questionnaire (GEQ; Carron et al., 1985). Participants responded on a nine-point Likert scale ranging from strongly disagree (1) to strongly agree (9). Possible averaged scores ranged from 1 to 9. Low scores were indicative of low cohesion and high scores were indicative of high cohesion. Alpha reliability estimates for the subscales of the GEQ in the current study were as follows: ATG-S: .61, ATG-T: .61, GI-S: .74, and GI-T: .79, consistent with previous measurements of alpha reliability of the GEQ (Carron et al., 2002). Brawley, Carron, and Widmeyer (1987) have also demonstrated evidence of predictive validity, concurrent validity, and discriminant validity of the GEQ. 
Demographic Questionnaire. The demographic questionnaire consisted of seven questions including age, class year, varsity sports participated in, length of participation on collegiate teams, and length of total participation in the sport(s). Additional items included whether they personally know any LGBT individuals, estimated number of how many LGBT individuals they personally know, and sexual orientation.

\section{Procedures}

After receiving IRB approval, as well as permission from the ADs, the head coaches were emailed and asked to provide a brief description of the study and the URL of the study to their female student-athletes. The questionnaires were hosted through the Statistical Package for the Social Sciences (SPSS) Data Collection Server Administration. No identifying information of the participants was collected. On the first page of the survey, participants were shown an informed consent form and asked to check the box at the bottom of the page to indicate that they were willing to participate in the study. Once they checked the box, they were directed to the set of questionnaires. At the completion of data collection, the data were downloaded from the SPSS server into an SPSS compatible file for statistical analysis.

\section{Statistical Analysis}

Responses to each of the questionnaires were entered into SPSS version 21.0. After reviewing the data for normality and homoscedasticity, descriptive statistics were run. A canonical correlational analysis was conducted to assess the relationship between the subscales of the HAS-L and GEQ. An a priori alpha level was set at .05.

\section{Results}

Average scores of the HAS-L subscales and the GEQ subscales are provided in Table 1. The average scores for the HAS-L subscales ranged from $1.28(S D=0.47)$ to 2.10 $(S D=0.81)$. Generally, participants reported low heterosexist attitude scores. In testing Hypothesis 1, a canonical correlation analysis was conducted to determine if a linear relationship existed between the two sets of variables (i.e., the subscales of the HAS-L and the subscales of the GEQ). The combination of the four canonical variates was statistically significant, $\Lambda=.91, F(16.00,1873.38)=3.79, p<.001$, $\eta^{2}=.07$. After the first variate was removed, the remaining three variates were not statistically significant, therefore the remaining nonsignificant variates were not interpreted. Using a cut-off value of .30 (Tabachnick \& Fidell, 2013) for the correlations, all variables were included in the interpretation of the first variate. The eigenvalue for the first variate was 0.07 and the canonical correlation coefficient was .27. Overall, it was found that as heterosexist attitudes increased, individual perception of team cohesion decreased, explaining approximately seven percent of team cohesion. Hypothesis 1 was supported. The results of the canonical correlation analysis are presented in Table 2. To test Hypotheses 2, 3, and 4, the magnitude and direction of the canonical correlations were examined to determine the contribution of each subscale to the variate. All four heterosexist attitudes subscales moderately correlated to the variate (all $r_{c} s>.50$ ), but Language Behaviors had 
the strongest correlation $\left(r_{c}=.86\right)$. The Inclusion Behaviors subscale $\left(r_{c}=.68\right)$ and Cognitive/Affective subscale $\left(r_{c}=.66\right)$ also had strong contributions to the variate. Partial support for Hypothesis 2 was found, as the Cognitive/Affective subscale provided substantially to the correlation. Social cohesion did moderately correlate with heterosexist behaviors, (ATG-S: $r_{c}=-.38$; GI-S: $r_{c}=-.33$ ), providing support for hypothesis 3 . ATG-T and GI-T had the strongest correlation with the variate $\left(r_{c} s=-.89\right.$ and -.84 , respectively), suggesting that heterosexist attitudes strongly negatively correlated with the two task components of team cohesion. Evidence was found to support hypothesis 4 .

\section{Discussion}

The purpose of this study was to examine the quantitative relationship between heterosexist attitudes and team cohesion in women's collegiate athletics. Evidence for the first hypothesis was found: as individual heterosexist attitudes increased, one's perception of team cohesion decreased. Overall, female student-athletes who held greater heterosexist attitudes (i.e., privileging heterosexuality and deeming other forms of sexual orientation as less than) reported lower perception of affiliation or less united with their team. An explanation of these findings could be drawn from the Social Identity Approach (Abrams \& Hogg, 2004; Hogg \& Abrams, 1988; Krane \& Kaus, 2014; Tajfel \& Turner, 1979). A female student-athlete is motivated to maintain self-concept. As described in the outset of this paper, women's collegiate athletics has been historically linked with lesbianism (Cahn, 1993; Griffin, 1998). An athlete who has internalized sexual prejudice may feel that her team or sport's

\section{Table 1 Descriptive Statistics for Heterosexist Attitudes in Sport-Lesbian Subscale Scores and Cohesion Subscale Scores for Study $2(N=621)$}

\begin{tabular}{lcccc}
\hline Variable & Mean & $s$ & Skewness & Kurtosis \\
\hline CogAff & 2.10 & 0.81 & 0.66 & 0.11 \\
LB & 1.91 & 0.65 & 1.40 & 2.14 \\
IB & 1.28 & 0.47 & 1.88 & 3.69 \\
ALL & 1.75 & 0.70 & 0.94 & 0.42 \\
ATG-S & 7.30 & 1.49 & -1.14 & 1.49 \\
ATG-T & 7.14 & 1.60 & -0.88 & 0.42 \\
GI-S & 6.71 & 1.70 & -0.61 & -0.12 \\
GI-T & 6.77 & 1.51 & -0.56 & -0.09 \\
Cohesive & 7.55 & 1.64 & -0.82 & 0.70 \\
Comfort & 8.03 & 1.96 & -1.08 & 0.75 \\
\hline
\end{tabular}

Note. CogAff = Cognitive Affective; $\mathrm{LB}=$ Language Behaviors; IB = Inclusion Behaviors; ALL = Avoidance of the Lesbian Label; ATG-S = Attraction to Group-Social; ATG-T = Attraction to Group-Task; GI-S = Group Integration-Social; GI-T = Group Integration-Task; Cohesive = "One a 1-10 scale, how cohesive is your team"; Comfort = "On a 1-10 scale, how comfortable is your team with lesbian teammate 


\section{Table 2 Correlations, Standardized Canonical Coefficients, Canonical Correlations, Proportions of Variance, and Redundancy Between Heterosexist Attitudes and Cohesion Variables and the Corresponding Variate}

\begin{tabular}{lcc}
\hline & \multicolumn{2}{c}{ First Canonical Variate } \\
\cline { 2 - 3 } & Correlation & Coefficient \\
\hline HAS-L Set & .66 & .29 \\
CogAff & .86 & .64 \\
LB & .68 & .39 \\
IB & .53 & -.03 \\
ALL & .48 & \\
$\quad$ Proportion of Variance & .03 & \\
$\quad$ Redundancy & & .04 \\
GEQ Set & -.38 & -.39 \\
ATG-S & -.89 & .11 \\
ATG-T & -.33 & -.41 \\
GI-S & -.84 & \\
GI-T & .44 & \\
$\quad$ Proportion of Variance & .03 & \\
Redundancy & .26 & \\
Canonical Correlation & & \\
\hline
\end{tabular}

Note. HAS-L = Heterosexist Attitudes in Sport—Lesbian scale; CogAff = Cognitive Affective subscale; $\mathrm{LB}=$ Language Behaviors subscale; $\mathrm{IB}=$ Inclusion Behaviors subscale; $\mathrm{ALL}=$ Avoidance of the Lesbian Label subscale; GEQ = Group Environment Questionnaire; ATG-S = Attraction to Group Social subscale; ATG-T = Attraction to Group Task; GI-S = Group Integration Social; GI-T = Group Integration Task.

association with the lesbian label threatens her self-concept. She might then choose to distance herself from a strong affiliation or integration with the team.

Partial support was also found for the second hypothesis. While behavioral heterosexist attitudes did most strongly correlate with team cohesion, all four measured subscales (Language Behaviors, Inclusion Behaviors, Cognitive/Affective, and Avoidance of the Lesbian Label) did contribute to the relationship and the Cognitive/Affective subscale demonstrated a strong relationship. It is not surprising that heterosexist behaviors were the two largest contributors to the relationship between the two constructs. Behaviors are salient and consequently more likely to influence social categorization and group dynamics than one's internal thoughts and emotions. In relation to Social Identity Approach, as one engages in overtly heterosexist behaviors toward members of her own team, such as using pejorative language or choosing to exclude another individual, her ability to perceive closeness or affinity to that team will be diminished. Previous researchers have found that female athletes engage in specific behaviors to diminish their attachment to their sport affiliation. For example, in Kauer and Krane (2006), student-athletes reported 
not wearing team paraphernalia or purposefully not identifying as an athlete in other social situations to avoid the lesbian label associated with their participation in sport, both visible demonstrations of diminished individual attraction to group. While the effect size was small, with seven percent shared variance between heterosexist attitudes and team cohesion, this is the first study to statistically identify any relationship between heterosexist attitudes and team cohesion hypothesized by previous researchers (Adams \& Anderson, 2012; Forbes et al., 2002; Stoelting, 2011; Vealey, 1997).

An alternative explanation for the small amount of shared variance and the magnitude of the HAS-L correlations is also plausible. Overall, participants reported moderate to low levels of heterosexist attitudes, consistent with recent research indicating a shift in acceptance toward lesbian athletes within the domain of women's athletics (Roper \& Halloran, 2007; Stoelting, 2011). The small correlational relationship may be representative of increased normalization of acceptance and inclusion of various sexual orientations within the make-up of a team. With normalization of a homo-positive atmosphere, overtly hostile attitudes toward lesbian teammates would not be present to disrupt the team environment and hurt team cohesion. As student-athletes demonstrate an increased level of acceptance through their behaviors, the team would become the most salient and important social identity, instead of heterosexual female athlete. In accordance with Social Identity Approach, strengthening ties through the team would be the optimal path to achieving self-concept.

Similar explanations have been found in other studies. Kauer and Krane (2006) noted that heterosexual student-athletes in their study learned to ignore the lesbian label stereotype over time. Other researchers demonstrated that increased disclosure of sexual orientation among lesbian athletes increased both self-acceptance of lesbian athletes and team acceptance of variant sexual identities (Kauer \& Krane, 2006; Stoelting, 2011). Improved attitudes of coaches (Oswalt \& Vargas, 2013; Vargas-Tonsing \& Oswalt, 2009) and female student-athletes (Roper \& Halloran, 2007; Southall et al., 2009) could play a role in improving team cohesion where heterosexist attitudes are minimal. In the current study most student-athletes reported knowing at least one LGBT individual. On average, they reported knowing approximately 11 LGBT people. It is possible that for some of the participants those LGBT individuals were teammates, given previous reports of lesbian participation in sport (Elling \& Janssens, 1999; Litchfield, 2011; Stoelting, 2011). Exposure is possibly a moderating factor, although not adequately measured in this study.

The purpose of Hypotheses 3 and 4 were to more specifically examine the components of team cohesion to better understand how heterosexist attitudes influence an important construct in Sport Psychology. It was expected that heterosexist attitudes would negatively correlate with social and task elements of team cohesion. In the current study heterosexist attitudes were most strongly associated with the task components of team cohesion. The relatively low association between heterosexist attitudes and social cohesion is consistent with previous findings presented by Forbes et al. (2002), but inconsistent with the theorizing of many qualitative researchers. Perhaps engaging on a daily basis with teammates (perceived to be lesbian or not) mitigates negative attitudes toward the individual. Krane (1997) described that while teammates of the lesbian athletes did demonstrate general homophobic and heterosexist behaviors (e.g., making jokes and using derogatory 
language toward lesbians), they appeared to accept their teammates, almost as an exception to the rule. Therefore, student-athletes with heterosexist attitudes in the current study may have normalized their teammates, even if they have not accepted a lesbian sexual orientation as normal, resulting in limited influence on social aspects of team cohesion.

The normalization of acceptance over intolerance in sport by athletes and coaches described earlier may have played a role in the findings that task cohesion was strongly related to heterosexist attitudes. One possible explanation can be found in the Sport Management literature. As described previously, Cunningham (2011b) demonstrated a link between inclusive environments and performance. Athletic department performance (as measured by National Association collegiate Director's Cup Points) increased when the department reported both high sexual orientation diversity and a strategy in place to foster diversity among members of the department. By itself, diversity of sexual orientation did not significantly improve performance when compared with departments with lower levels of sexual orientation diversity. A significant improvement was found when the department actively encouraged diversity and developed an inclusive work atmosphere. When making analogies to the athletic team setting, diversity of sexual orientation on the team alone would not be expected to influence performance. Like the diversity strategy in the Cunningham (2011b) study, if coaches or peer-leaders fostered a homo-positive environment, a lack of heterosexist behaviors to disrupt the environment may allow the team to better focus on its task objectives and endeavors. Heterosexist attitudes would be perceived as a disturbance to the team's end goal, resulting in a possible deterioration of task cohesion.

The findings from this paper have important implications for a number of sport-related professions, as they may provide greater understanding of the influence of sexual prejudice on group dynamics. Researchers and practitioners in sport should note that the relationships with heterosexism focused primarily on the task components. Consequently, the need for educating student-athletes in acceptance goes beyond mere "getting along" and figures into the team performance equation. Normalizing a homo-positive atmosphere and rejecting homo-negative behaviors could play a role in uniting team members to the goal of working together toward skill improvement and ultimately winning. Implications for administrators also exist. To educate students and coaches on the needs for inclusion and diversity, greater buy-in may be achieved if constituents are aware of the potential relationships with performance-related variables. In addition, administrators may be less likely to suppress the visibility of their lesbian and gay male staff or athletes out of fear that it will lead to disruption of the group as seen in previous research (Calhoun et al., 2011; Melton \& Cunningham, 2012).

A few limitations in this paper must be addressed. The analysis presented in this paper is correlational, and therefore no causation can be implied. No attempt was made to control for time of season or proximity to competition or length of time on the team. As performance and experience have been shown to influence cohesion (Carron et al., 2002), those variables may have been confounding factors in the current study. When reviewing the heterosexist attitudes data, a floor effect occurred, where a majority of participants indicated low heterosexist attitudes. The skewed distribution was unable to be corrected via transformation. Consequently, the restricted range of the data may have influenced the correlation analysis and 
the ability to precisely measure the amount of shared variance between heterosexist attitudes and team cohesion. Replication of these findings is needed.

Based on the outcomes of the current study, researchers in sport-related professions should continue to examine how heterosexist attitudes influence group dynamics and other performance related variables, such as self-concept. In addition, it was suggested that a more inclusive normative culture in women's athletics could explain the findings in the current study. However, neither exposure to lesbian teammates nor the extent to which a team considered itself inclusive or accepting were adequately measured in the current study. Future researchers should examine exposure and inclusivity as potential moderating variables.

\section{Conclusion}

The current study is the first to quantitatively demonstrate a statistical negative relationship between heterosexist attitudes and team cohesion in women's collegiate athletics. Historically, lesbians have been overtly discouraged from openly identifying as gay or lesbian to avoid tarnishing the reputation of the program or disrupting team cohesion (Krane, 1997). More recent researchers have indicated that disclosure may be more beneficial to the development of team cohesion (Adams \& Anderson, 2012; Kauer, 2009; Stoelting, 2011). In recent years, a number of high profile female athletes have disclosed their sexual identity, such as WNBA player Britney Griner, USA National Soccer team members Abby Wambach and Megan Rapinoe, Canadian National Hockey team member Sarah Vaillancourt, and tennis player Amelie Mauresmo, to name a few, changing the landscape of what is considered acceptable in women's athletics. Many more collegiate student-athletes have likely disclosed to their teammates (Fink et al., 2012; Kauer \& Krane, 2006). The existence of lesbian athletes can no longer be silenced as it has in the past. Athletic administrators and head coaches must address the issue of diversity and inclusion, recognizing that promoting a homo-positive atmosphere among their student-athletes is ultimately in the best interest of the institution, team, and studentathletes. As institutions look to increase acceptance of diversity by implementing education programs for their student-athletes, this study may provide additional incentive. First and foremost, the education of a culturally competent student-athlete should be the goal of implementing these programs. However, teams may be able to realize the benefits of improved team cohesion and performance as well.

\section{References}

Abrams, D., \& Hogg, M.A. (2004). Metatheory: Lessons from social identity research. Personality and Social Psychology Review, 8(2), 98-106. PubMed doi:10.1207/ s15327957pspr0802_2

Acosta, R.V., \& Carpenter, L.J. (2014). Women in intercollegiate sport: A longitudinal, national study thirty-seven year update. Retrieved from: www.acostacarpenter.org.

Adams, A., \& Anderson, E. (2012). Exploring the relationship between homosexuality and sport among teammates of a small, Midwestern Catholic college soccer team. Sport Education and Society, 17(3), 347-363. doi:10.1080/13573322.2011.608938

Anderson, E. (2009). Inclusive masculinity: The changing nature of masculinities. New York, NY: Routledge. 
Blinde, E.M., \& Taub, D.E. (1992). Homophobia and women's sport: The disempowerment of athletes. Sociological Focus, 25(2), 151-166. doi:10.1080/00380237.1992.10570613

Brawley, L.R., Carron, A.V., \& Widmeyer, W.N. (1987). Assessing the cohesion of teams: Validity of the Group Environment Questionnaire. Journal of Sport Psychology, 9, 275-294.

Bruner, M.W., Dunlop, W.L., \& Beauchamp, M.R. (2014). A social identity perspective on group processes in sport and exercise. In M.R. Beauchamp \& M.A. Eys (Eds.), Group dynamics in sport and exercise sport psychology (pp. 20-249). London, UK: Routledge.

Cahn, S.K. (1993). From the "muscle moll" to the "butch" ballplayer: Mannishness, Lesbianism, and homophobia in U.S. women's sport. Feminist Studies, 19(2), 343-371. doi: $10.2307 / 3178373$

Calhoun, A.S., LaVoi, N.M., \& Johnson, A. (2011). Framing with family: Examining online coaches' biographies for heteronormative and heterosexist narratives. International Journal of Sport Communication, 4, 300-316.

Carron, A.V., Brawley, L.R., \& Widmeyer, N.W. (2002). The Group Environment Questionnaire test manual. Morgantown, WV: Fitness Information Technology.

Carron, A.V., Widmeyer, W.N., \& Brawley, L.R. (1985). The development of an instrument to assess cohesion in sports teams: The Group Environment Questionnaire. Journal of Sport Psychology, 7, 244-266.

Cunningham, G.B. (2011a). Creative work environments in sport organizations: The influence of sexual orientation diversity and commitment to diversity. Journal of Homosexuality, 58, 1041-1057. PubMed doi:10.1080/00918369.2011.598413

Cunningham, G.B. (2011b). The LGBT advantage: Examining the relationship among sexual orientation diversity, diversity strategy, and performance. Sport Management Review, 14, 453-461. doi:10.1016/j.smr.2010.11.003

Cunningham, G.B., \& Melton, E.N. (2011). The benefits of sexual orientation diversity in sport organizations. Journal of Homosexuality, 58, 647-663. PubMed doi:10.1080/0 0918369.2011 .563664

Elling, A., \& Janssens, J. (2009). Sexuality as a structural principle in sport participation: Negotiating sport spaces. International Review for the Sociology of Sport, 44(1), 71-86. doi:10.1177/1012690209102639

Fink, J.S., Burton, L.J., Farrell, A.O., \& Parker, H.M. (2012). Playing it out: Female intercollegiate athletes' experiences in revealing their sexual identities. Journal for the Study of Sports and Athletes in Education, 6(1), 83-106. doi:10.1179/ssa.2012.6.1.83

Fisher, L.A., Knust, S.K., \& Johnson, A.J. (2013). Theories of gender and sport. In E. Roper (Ed.), Gender relations in sport (pp. 21-38). Rotterdam, Netherlands: Sense Publishers. doi:10.1007/978-94-6209-455-0_2

Forbes, S.L., Stevens, D.E., \& Lathrop, A.H. (2002). A pervasive silence: Lesbophobia. Canadian Women's Studies, 21(3), 32-35.

Griffin, P. (1998). Strong women: Deep closets. Champaign, IL: Human Kinetics.

Hawes, K. (2001). H - The scarlet letter of sports: More people in athletics say it's time to start talking openly about homophobia. NCAA News, 38, 13-14.

Herek, G.M. (2000). The psychology of sexual prejudice. Current Directions in Psychological Science, 9(1), 19-22. doi:10.1111/1467-8721.00051

Herek, G.M., \& McLemore, K.A. (2011). The Attitudes toward Lesbians and Gay Men (ATLG) scale. In T. D. Fisher, C. M. David, W. L. Yarber, \& S. L. Davis (Eds.), Handbook of sexuality-related measures (3rd Ed., pp. 415-417). Oxford, England: Taylor \& Francis.

Hogg, M.A., \& Abrams, D. (1988). Social identification: A social psychology of intergroup relations and group processes. London, UK: Routledge.

Kauer, K.J. (2009). Queering lesbian sexualities in collegiate sporting spaces. Journal of Lesbian Studies, 13(3), 306-318. PubMed doi:10.1080/10894160902876804

Kauer, K.J., \& Krane, V. (2006). "Scary dykes" and "feminine queens:" Stereotypes and female collegiate athletics. Women in Sport and Physical Activity Journal, 15(1), 42-55. 
Kauer, K.J., \& Krane, V. (2013). Sexuality identity and sport. In E. Roper (Ed.), Gender relations in sport (pp. 53-72). Rotterdam, Netherlands: Sense Publishers. doi:10.1007/97894-6209-455-0_4

Kinsey, A.C., Pomeroy, W.R., \& Martin, C.E. (1948). Sexual behavior in the human male. Philadelphia, PA: W. B. Saunders.

Krane, V. (1997). Homonegativism experienced by lesbian collegiate athletes. Women in Sport and Physical Activity Journal, 6(2), 165-188.

Krane, V. (2001). One lesbian feminist epistemology: Integrating feminist standpoint, queer theory, and feminist cultural studies. The Sport Psychologist, 15, 401-411.

Krane, V., Choi, P.Y.L., Baird, S.M., Aimar, C.M., \& Kauer, K.J. (2004). Living the paradox: Female athletes negotiate femininity and muscularity. Sex Roles, 50(5/6), 315-329. doi:10.1023/B:SERS.0000018888.48437.4f

Krane, V., \& Kauer, K.J. (2007). Out on the ball fields: Lesbians in sport. In V. Clarke \& E. Peel (Eds.), Out in psychology: Lesbian, gay, bisexual, trans and queer perspectives. West Sussex, England: John Wiley \& Sons. doi:10.1002/9780470713099.ch13

Krane, V., \& Kaus, R.J. (2014). Gendered social dynamics in sport. In M. R. Beauchamp and M. A. Eys (Eds.), Group dynamics in sport and exercise sport psychology (pp. 1,099-1149). London, UK: Routledge.

Litchfield, C. (2011). Finding safe and affirming spaces in women's field hockey. The International Journal of Sport and Society, 2(3), 35-46.

Melton, E.N., \& Cunningham, G.B. (2012). When identities collide: Exploring minority stress and resilience among college athletes with multiple marginalized identities. Journal for the Study of Sports and Athletes in Education, 6(1), 45-66. doi:10.1179/ssa.2012.6.1.45

Mullin, E.M. (2013). Scale development: Heterosexist attitudes in women's collegiate athletics. Measurement in Physical Education and Exercise Science, 17(1), 1-21. doi $: 10.1080 / 1091367 X .2013 .741357$

Mullin, E.M. (2016). Further reliability and validity of the Heterosexist Attitudes in Sport - Lesbian scale. Women in Sport and Physical Activity, 24(1), 26-34. doi:10.1123/ wspaj.2014-0051

Oswalt, S.B., \& Vargas, T.M. (2013). How safe is the playing field? Collegiate coaches' attitudes towards gay, lesbian, and bisexual individuals. Sport in Society, 16(1), 120-132. doi:10.1080/17430437.2012.690407

Raja, S., \& Stokes, J.P. (1998). Assessing attitudes towards lesbians and gay men: The Modern Homophobia Scale. Journal of Gay, Lesbian, and Bisexual Identity, 3(2), 113-134.

Roper, E.A., \& Halloran, E. (2007). Attitudes towards gay men and lesbians among heterosexual male and female student-athletes. Sex Roles, 57, 919-928. doi:10.1007/ s11199-007-9323-0

Rotella, R.J., \& Murray, M. (1991). Homophobia, the world of sport, and sport psychology consulting. The Sport Psychologist, 5, 355-364.

Sartore, M.L., \& Cunningham, G.B. (2009). The lesbian stigma and the sport context: Implications for women of every sexual orientation. Quest, 61, 289-305. doi:10.108 0/00336297.2009.10483617

Shakib, S. (2003). Female basketball participation: Negotiating the conflation of peer status and gender status form childhood through puberty. The American Behavioral Scientist, 46, 1405-1422. doi:10.1177/0002764203046010008

Southall, R. M., Nagel, M. S., Anderson, E. D., Polite, F. G., \& Southall, C. (2009). An investigation of male college athletes' attitudes towards sexual orientation. Journal of Issues in Intercollegiate Athletics, 2009 Special Issues, 62-77.

Stoelting, S. (2011). Disclosure as interaction: Why lesbian athletes disclose their sexual identities in intercollegiate sport. Journal of Homosexuality, 58(9), 1187-1210. PubMed doi:10.1080/00918369.2011.605731

Tabachnick, B.G., \& Fidell, L.S. (2013). Using multivariate statistics (6th ed.). Boston, MA: Pearson. 
Tajfel, H., \& Turner, J.C. (1979). An integrative theory of intergroup conflict. In W.G. Austin \& S. Worchel (Eds.), The social psychology of intergroup relations (pp. 33-47). Monterey, CA: Brooks/Cole.

Turner, J.C. (1987). Rediscovering the social group: A self categorization theory. New York, NY: Basil Blackford Ltd.

Vargas-Tonsing, T.M., \& Oswalt, S.B. (2009). Coaches' efficacy beliefs towards working with gay, lesbian, and bisexual athletes. International Journal of Coaching Science, 3(2), 29-42.

Vealey, R.S. (1997). Transforming the silence on lesbians in sport: Suggested directions for theory and research in sport psychology. Women in Sport and Physical Activity Journal, 6(2), 164-188.

Weinberg, G. (1972). Society and the healthy homosexual. New York, NY: St. Martins.

Wellman, S., \& Blinde, E. (1997). Homophobia in women's intercollegiate basketball: Views of women coaches regarding coaching careers and recruitment of athletes. Women in Sport and Physical Activity Journal, 6(2), 63-82.

Wolf-Wendel, L.E., Toma, J.E., \& Morphew, C. (2001). How much difference is too much difference? Perceptions of gay men and lesbians in intercollegiate athletics. Journal of College Student Development, 42(5), 465-479.

Zanna, M.P., \& Rempel, J.K. (1988). Attitudes: A new look at an old concept. In D. BarTal \& A.W. Kruglanski (Eds.), The social psychology of knowledge (pp. 315-334). Cambridge, England: Cambridge UP. 